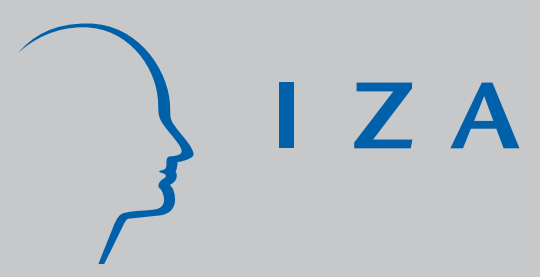

IZADP No. 2768

Like Mother Like Son? Experimental Evidence on the Transmission of Values from Parents to Children

Marco Cipriani

Paola Giuliano

Olivier J eanne

April 2007 


\title{
Like Mother Like Son? Experimental Evidence on the Transmission of Values from Parents to Children
}

\author{
Marco Cipriani \\ George Washington University \\ Paola Giuliano \\ Harvard University, IMF and IZA \\ Olivier Jeanne \\ IMF
}

Discussion Paper No. 2768

April 2007

IZA

P.O. Box 7240

53072 Bonn

Germany

Phone: +49-228-3894-0

Fax: +49-228-3894-180

E-mail: iza@iza.org

Any opinions expressed here are those of the author(s) and not those of the institute. Research disseminated by IZA may include views on policy, but the institute itself takes no institutional policy positions.

The Institute for the Study of Labor (IZA) in Bonn is a local and virtual international research center and a place of communication between science, politics and business. IZA is an independent nonprofit company supported by Deutsche Post World Net. The center is associated with the University of Bonn and offers a stimulating research environment through its research networks, research support, and visitors and doctoral programs. IZA engages in (i) original and internationally competitive research in all fields of labor economics, (ii) development of policy concepts, and (iii) dissemination of research results and concepts to the interested public.

IZA Discussion Papers often represent preliminary work and are circulated to encourage discussion. Citation of such a paper should account for its provisional character. A revised version may be available directly from the author. 


\section{ABSTRACT \\ Like Mother Like Son? Experimental Evidence on the Transmission of Values from Parents to Children*}

This paper studies whether prosocial values are transmitted from parents to their children. We do so through an economic experiment, in which a group of Hispanic and African American families play a standard public goods game. The experimental data presents us with a surprising result. We find no significant correlation between the degree of cooperation of a child and that of his or her parents. Such lack of cooperation is robust across age groups, sex, family size and different estimation strategies. This contrasts with the typical assumption made by the theoretical economic literature on the inter-generational transmission of values. The absence of correlation between parents' and children's behavior, however, is consistent with part of the psychological literature, which emphasizes the importance of peer effects in the socialization process.

JEL Classification: $\quad$ C92, H41, Z1

Keywords: culture, intergenerational transmission, public good games

Corresponding author:

Paola Giuliano

Department of Economics

Harvard University

Cambridge, MA 02138

USA

E-mail: giuliano@fas.harvard.edu

\footnotetext{
* This project was completed while Olivier Jeanne was visiting the Department of Economics of Princeton University, whose hospitality is gratefully acknowledged. We thank José Romero for excellent research assistance. We are extremely grateful to the principal of the Bruce Monroe Elementary School, Dr Palacio, and to the school's children-parents coordinator, Ms Hernandez; without both of them and their enthusiasm, this work would not have been possible. We also thank all the parents and children participating in the experiment, who have been extremely enjoyable to work with. Finally, this work benefited from the comments of George Akerlof, Alberto Bisin, Pedro dal Bo, Antonio Guarino, Steffen Huck, David Laibson, Thomas Palfrey, David Ribar, Alvin Roth and Thierry Verdier. All remaining errors are ours. The views expressed in this paper are those of the authors and should not be attributed to the International Monetary Fund, its Executive Board, or its Management.
} 


\section{Introduction}

A large and growing literature has found that cultural traits or values, such as trust, the propensity to cooperate and to free-ride on others are important determinants of economic outcomes, such as growth, economic development and international trade. ${ }^{2}$

But where do these differences in attitudes come from? The formation of individual values is a broad question that falls in the realm of several disciplines (including psychology, sociology, political science and economics). Social scientists generally view the family as a potentially important determinant of individual personality, beliefs and values. In particular, a large part of the psychological literature is devoted to understand better the extent and channels of family influence. This literature has not reached robust conclusions regarding the effect of parenting. On the one hand, Eisenberg and Mussen (1989) suggest that if parents are nurturing, generous and altruistic, their children may develop prosocial behavior, by adopting these characteristics through identification. On the other hand, the review of developmental behavioral genetics by Harris (1995) suggests that the socialization processes that most influence individual behavior are not the result of learning from one's parents, but take place primarily in childhood and adolescence peer groups. ${ }^{3}$

In the theoretical economic literature on the transmission of values, several economic models assume that the family is the primary locus of value transmission, posing that parents act consciously to socialize their children to particular cultural traits. For instance, in Bisin and Verdier (2000) the intergenerational transmission of cultural traits happens as a result of family socialization and intragroup marriages. Bisin and Verdier (2001) study the long run pattern of preferences in the population, in a model where parents socialize and transmit their preferences to their offspring. Corneo and Jeanne (2006) develop a theory of occupational choice in a model where values are endogenous and taught by parents to their children. Doepke and Zilibotti

\footnotetext{
2 Cultural differences across countries have been considered an important determinant of differences in economic growth rates (Putnam at al, 1994; La Porta et al, 1997; Knack and Keefer, 1997; Zak and Knak, 2001; Tabellini, 2005), trade flows (Fershtman and Gneezy, 2001; Bornhorst et al. 2004; Guiso at al., 2004) and financial development (Guiso at al., 2005).

${ }^{3}$ In the political science literature, Hyman (1959) has argued that the family is the primary agent of political socialization. Through an empirical analysis, Jennings and Niemi (1968) find that the correlation in political values between children and their parents is strong on concrete issues (such as allowing prayers in schools), but almost zero on more abstract ones (such as party affiliation).
} 
(2005) explain the economic decline of the aristocracy during the industrial revolution with a model where altruistic parents can affect their offspring's' degree of patience.

Although the assumption that values relevant for economic behavior are transmitted from parents to children is very pervasive in the theoretical economics literature, the empirical evidence on it is almost non existent. Our paper tries to start filling this gap, by gathering experimental data on Hispanic and African American parents and children from a public school in Washington, DC. Since we focus on minority families, our experimental data will allow us to answer also another important question: whether it is true that the degree of prosociality is lower in the minority population than in the general US population.

In the experiment, we study whether the propensity to cooperate is transmitted from parents to their children, by having them play a standard public goods game: each subject is given a money endowment and asked to share it between him or herself and a group fund. We take the contribution of an individual to the group as an indicator of his or her "prosociality," i.e., a reflection of his or her values regarding the importance of contributing to the common good. ${ }^{4}$ We would expect altruistic people to contribute to the group fund, and self-interested subjects to free-ride. We measure the correlation between the prosociality of a parent and that of his or her child, in order to gauge the extent to which it is transmitted across generations. If selfinterest is a family-transmitted value, we would expect a positive correlation between the behavior of parents and their children during the game.

There is a very large literature on public goods experiments. ${ }^{5}$ These papers, mainly run with US undergraduates, tend to show that contributions range between one third and two third of the endowment. These results are usually interpreted as a proof that subjects' choices are partially determined by altruism. The experimental literature on children's behavior is, instead, relatively recent. Harbaugh and Krause (2000) have contrasted the behavior of children with that of adults, and found a similar level of contribution. Peters et al (2004) found that both parents and children contributed more to a public good fund when their group consisted of family members than when the group consisted of strangers. Ours is the first paper to study the correlation between the behavior of children and that of their parents in an experimental setup.

\footnotetext{
${ }_{4}^{4}$ Prosocial behavior is defined as "voluntary actions that are intended to help or benefit another individual or group of individuals" (Eisenberg and Mussen, 1989).

${ }^{5}$ For a review of these experiments see Ledyard (1995).
} 
The experimental data presented us with a surprising result. There was no significant correlation between the prosociality of parents and that of their children. Our piece of evidence goes against the view that individual values are primarily the outcome of a simple process of transmission from the parents to their children - i.e., it is more consistent with the views of Harris (1995) than those of Eisenberg and Mussen (1989). Moreover, we also find that children with more siblings tend to contribute significantly less than children from smaller families, which is consistent with the idea that environmental stimuli (e.g., competition for resources with one's siblings) are more significant agents of value formation.

Therefore, at least in the African American and Hispanic population, the socialization processes that matter for economic behavior do not seem to take place inside the family. Further research is needed to gauge whether this result extends to other populations within the US (e.g., the white majority) and to other countries and whether there are other socializing factors (e.g., peer groups) that are important for the determination of individual values.

Our paper is the first to illustrate how experimental games can be designed to study how values are transmitted across generations. Alternatively, the extent of the intergenerational transmission of values can be estimated by gathering survey data. For instance, in a recent paper, Dohmen et al. (2006) report that children's trusting behavior, as measured by a survey, is strongly correlated to that of their parents. ${ }^{6}$ Our experiment adds additional evidence to this debate. The difference between their results and ours could be due to several competing reasons. First, the empirical evidence on whether surveys and experimental games capture the same individual characteristics is mixed. 7 This may happen because in surveys, as opposed to experiments, subjects are not remunerated (and therefore have no incentive) to choose what they consider to be the best answer.

Second, whereas we concentrate on the transmission of attitudes toward cooperation between parents and young children (we ran the experiment in a public elementary school), in

\footnotetext{
${ }^{6}$ Dohmen et al. (2006) also report a positive association between parents' and adult children's levels of risk aversion; similar results regarding the transmission of risk-taking behavior between parents and adult children have been found by Charles and Hurst (2003).

${ }^{7}$ Glaeser et al (2000) find that survey-based measures of trusting attitudes are not significantly related to individual behavior in a trust game; in contrast, Anderson et al (2004) find that survey-based attitudinal or behavioral measures of trust are significant determinants of contribution levels in a canonical publicgoods experiment.
} 
Dohmen et al.'s survey children are much older (their average age is 23).8 On the one hand, it is possible that the transmission of cultural traits across generations happens when children are young adults; on the other hand, it is also possible that whatever correlation exists between adult children and parents, is not due to parents' influence over their children, but to the fact that children's socialization outside the family nevertheless happens within the same community in which their parents live.

Third, our experimental sample is constituted by African American and Hispanic families, whereas Dohmen et al.'s survey is representative of the German population. As we wrote above, it is possible that the degree to which values are transmitted across generations changes across countries, ethnicities and levels of income. ${ }^{9}$

The paper is structured as follows. Section 2 presents the main features of our experiment, Section 3 reports our results, Section 4 concludes.

\section{The Experiment}

\subsection{Recruitment and sample description}

The families participating in the experiment were recruited at Bruce Monroe Elementary School, a public elementary school in Washington, DC. A parent meeting takes place each week at Bruce Monroe from 8:30 a.m. to 10:30 a.m.; all parents in the school can attend the meeting. Before each session of the experiment, the children-parents coordinator advertised the experiment distributing flyers in class and calling parents from the school list. After the parents had played we gathered the children from their classes and ran the experiment with them.

We attended three parent meetings and were able to recruit 76 subjects, 38 children and 38 parents. A breakdown of the three sessions is presented in Table 1. All the parents were

\footnotetext{
8 Similarly, Fernandez et al, 2004 and Knowles and Postlewaite, 2005 have found evidence of family transmission respectively of individual preferences for mates and of consumption versus savings by comparing the behavior or parents with that of their adult children. These papers look at data at the individual level (e.g., in the case of Fernandez et al.' s paper, whether the wives of those whose mother are workers work) in order to gauge the intergenerational transmission of cultural preferences.

${ }^{9}$ For instance, Henrich et al. (2001) found that there is considerable variability in the degree of altruism, as measured by dictator, ultimatum or public games, among 15 small-scale tribal societies.
} 
mothers, except for one father ${ }^{10}$. Moreover, one of the parents was the child's grandmother, whom we accepted in the experiment because she raised her grandchild.

Before running the experiment, we asked parents to fill out a questionnaire where we gathered information about their demographic characteristics and those of their children. Table 2 presents the results of the questionnaire. Seventy-six percent of subjects are Hispanics and the rest African Americans. This reflects the fact that the vast majority of the students at Bruce Monroe are either Hispanic (about 50 percent) or African-American (in total those two ethnicities constitute 98 percent of the student body).

The parents' average age is 36 years and ranges between 24 and 63. Fifty percent of them are married, twenty-six percent are single mothers and the rest are divorced, widowed or separated. The average number of children in each family is relatively high (3.26), ranging from a minimum of 1 to a maximum of 10 . Both the relatively low percentage of married families and the relatively high number of children are in line with the demographic characteristics of African American and Hispanic families in the United States. Finally, $84 \%$ of the parents indicate that they follow a religion.

As for the children, 39 percent of them are girls. The children's level of education goes from zero (Pre-K) to sixth grade; the average school grade is 2.66 .

\subsection{The Game}

We run a standard public goods game. In a public goods game, subjects are put into groups of size $n$ and endowed with an initial amount of tokens. Subjects need to choose whether to keep those tokens for themselves or to contribute to the group fund. Contributions to the group are multiplied by a parameter, $a$, which is greater than one and less then $n$, and then divided equally among the group members. The marginal private return to a contribution is the ratio $a / n<1$. The socially optimal solution is to contribute the full endowment to the group fund, since $a$ is greater than one, whereas the dominant strategy for self-interested subjects is to contribute nothing, as $a$ is smaller then $n$.

In our experiment, we chose $a=2$ and assigned people to groups of four subjects (this implies a marginal private return of $1 / 2)^{11}$. The assignment of subjects to different groups was

\footnotetext{
10 We tested the robustness of our results to excluding the father; none of our results is affected in a significant way (see the Addendum).
} 
done automatically by the computer and subjects were not told to which group they belonged. When the number of subjects was not divisible by 4, we constructed a "synthetic" group, using the decisions of randomly selected members of another group. ${ }^{12}$ To ensure that the behavior of parents and children is comparable, each subject's group in the children's session had the same composition as the subject's group in the parents' session. ${ }^{13}$

Note that we chose to run our experiment with a public goods game (as opposed to, say, a trust game or a dictator game) because this offered some advantages to the experimentalist. First, public goods games have been used before with children and in families, which gave us natural benchmarks of comparison in the literature. Second, a public goods game is symmetric (in the sense that everyone plays the same game) ${ }^{14}$ and can easily be repeated in several rounds, which is useful to generate more data given the constraint on the number of subjects.

\subsection{Implementation}

We ran three sessions of the experiment. Over the three sessions, all the parameters were kept the same (number of tokens, marginal private return, number of rounds and number of subjects per group). Nevertheless, since the number of parents participating in the meeting varied from one meeting to the other, the number of groups changed over the three sessions. Note that we did not allow a parent-child pair to participate in more than one session of the experiment. ${ }^{15}$ The three sessions took place on three different days. In a given day, we ran the

\footnotetext{
${ }^{11}$ In the linear public goods game literature there is a variety of choices with respect to $a$ and $n$. Our choices of $\mathrm{a}=2$ and $\mathrm{n}=4$ are somewhat middle of the ground.

12 There was one synthetic group (with one actual subject) in the first session, two synthetic groups (with three and one actual subject respectively) in the second session; there was no synthetic group in the third session. We had two synthetic groups in the second session because, after reading the instructions but before starting the game, one of the parents realized she would have had to leave in the middle of the game. One must notice that the contributions of the synthetic groups' virtual members did not respond to the other subject's (or subjects') behavior in the same way as in a regular group. Because of this difference between synthetic and regular groups it will be important to test the robustness of our results to the exclusion of synthetic groups (see the Addendum). Excluding synthetic groups reduces the number of subjects from 76 to 64 .

13 That is, the children of two parents playing in the same group also play in the same group. However, we took care of not reproducing the same seating arrangement with the children as with their parents.

${ }^{14}$ By contrast, for instance, a trust game has two types of players, the sender and the receiver, which reduces the data on which it is possible to compute the correlation.

15 That is, a parent was not allowed to participate twice with two different children. Moreover, if a parent participated in a session, the other parent was not allowed to participate in another session with a sibling.
} 
experiment with the parents first and then with their children. The parents and the children could not communicate about the game before the children played.

Each session took approximately two hours. The experiment was run in the following way:

Before starting the game, parents filled out a simple questionnaire. The questionnaire contained basic demographic questions (age, race, marital status, family composition, etc.).

$>$ The subjects were assigned a number.

$>$ We read the instructions aloud ${ }^{16}$. We read the same instructions to the parents and to the children. As standard in the experimental literature with children ${ }^{17}$, the instructions (available from the authors) were somewhat longer and contained more examples than those usually read in a public goods game. The explanation of the rules of the game took an average of 40 minutes. After reading the instructions, we asked the subjects whether they had questions and offered to answer them in private.

After explaining the game, subjects were seated and separated by partitions so that their actions would remain confidential. In his or her position, each subject had an envelope and a cup, both bearing the subject's number. The envelope was used for the tokens that the subjects wanted to share. The cup for the tokens (s)he wanted to keep for him(her)self

$>\mathrm{W}$ gave each subject 5 tokens. Then we told the subjects to decide how many tokens they wanted to share and put them in the envelope.

$>$ After subjects had made their choices, we collected the envelopes, computed the payoffs and returned the earnings to the subjects. ${ }^{18}$

$>$ We then distributed 5 new tokens to each subject and started a new round. The game was repeated 10 times.

Overall, subjects received 50 tokens; therefore, if everyone behaved cooperatively, the maximum possible gain was 100 tokens. After the experiment, we exchanged tokens for money

\footnotetext{
16 The instructions to the parents were read aloud both in English and in Spanish since not all the parents could speak English fluently.

17 See,e g., Harbaugh and Krause (2000).

${ }^{18}$ In the experiment, we used red tokens. Sometime, we had to return a subject half a token; in this case we used blue for half of a red token.
} 
at the exchange rate of $20 \phi$ per token for the parents and at the exchange rate of $10 \phi$ for token for the children. Children were not given real money, but vouchers that they could use to "buy" toys at the end of the experiment from a toy stand we had set up. Finally, parents received a show up fee of $\$ 12$ and children a show-up fee of one extra-toy in addition to those that they could buy.

\section{Results}

The main goal of our paper is to look at the relationship between the behavior of a child and that of his or her parent. Before we do this, however, it is useful to characterize the behavior of the parents and children separately, and compare it to the results that have been obtained in the literature on public goods games.

\subsection{Children's and Parents' Behavior}

The first row of Table 3 shows the average contribution across all rounds of parents and children. We find that the average contribution over all rounds is 2.90 for parents and 2.76 for children, 58 and 55 percent of the maximum amount (5 tokens). These numbers are in line with the results that have been obtained in the literature for similar games. ${ }^{19}$ Therefore, our findings show that the degree of cooperative behavior in both Hispanic and African American subjects is not different to that measured in other experiments covering representative samples of the US population. This contrasts with survey evidence on the degree of prosociality in minority groups. For instance, using data from the General Value Survey, Alesina and La Ferrara (2002) find that the level of trust is lower in minorities (and in African Americans in particular). The difference between our results and theirs may be explained by the fact that minorities are reluctant to cooperate with whites (since there are no whites in our sample), but willing to cooperate with other minorities.

The difference between the children's average contribution and the parents' average contribution is not statistically significant at the 10 percent level, using a Mann-Whitney test (p-

\footnotetext{
${ }^{19}$ In his review of the literature on public goods games Ledyard (1995) reports that total contributions in public goods games similar to ours can be expected to lie between 40 percent and 60 percent of the maximum contribution. That the contributions in our sample are close to the high end of this range might be due to group solidarity: our subjects may know each other (the children study in the same school) and, although separated by partitions, play in the same room. Physical proximity and group solidarity are known to increase the average contribution (see, e.g., Orbell et al, 1988).
} 
value 0.87).20 This is consistent with Harbough and Krause's (2000) finding that the level of altruistic behavior in children is similar to that of adults. The contribution of the children over the course of the game, however, is more variable than that of their parents, both in the crosssection and over time; the average standard deviation of contributions over the ten rounds is 1.08 for children and 0.80 for parents. ${ }^{21}$ Moreover, there is a difference between parents and children at the tails of the distribution. The share of parents who contribute more than 4 tokens and less than 1 token on average are respectively 16 percent and 8 percent; the same numbers are 24 percent and 11 percent in children. That is, there appears to be a higher proportion of "extreme contributions" in children than in parents. Indeed, we observe three cases of children contributing zero or five in all the rounds ${ }^{22}$, which never occurs in the case of the parents. ${ }^{23}$

We also analyzed the effect of our demographic variables on the average contribution. Table 4 shows children's average contribution broken down by race, number of siblings, whether the parent is religious or not ${ }^{24}$, sex and school grade. Boys seem to be less cooperative than girls, although the difference is not very large. This seems consistent with the literature on social psychology. Fabes and Eisenberg (1996) document that differences in actual behavior by sex are not strong; there is a general increase in sex differences (with women being more generous) with age, with pronounced differences arising only during adolescence.

Moreover, older children are significantly ${ }^{25}$ less cooperative that younger ones and African Americans are significantly less co-operative than Hispanics. There is not a meaningful difference between the levels of contribution of children coming from non religious families as

20 In order to have independent observations, we computed the parents' and children's average contributions by group and tested the null that their difference was different from zero.

${ }^{21}$ Using a Mann-Whitney test, such a difference comes out significant (pvalue equals 0.05).

22 One child contributing zero in all the rounds and two children contributing 5.

${ }^{23}$ Because of difference in standard deviation and proportion of extreme contributions, the hypothesis that the two distributions are identical can be rejected at the 1 percent level, using a KolmogorovSmirnov test.

${ }^{24}$ We divided the sample in two, according to whether the parent in the questionnaire indicated a religion or that they were non religious.

25 Table 3 reports the p-values for a Mann-Whitney test of the null that the mean be the same in the two sample of children. Note that the result of these tests on the demographic characteristics needs to be taken with a pinch of salt since the observations from children or parents belonging to the same group are not independent. However, the significance of the demographic characteristics is confirmed by the regression analysis described in the next section, where we correct for the dependence among subjects belonging to the same group. 
opposed to children coming from religious ones. Finally, children coming from larger families (more than 3 children $^{26}$ ) tended to contribute significantly less than children coming from smaller families.

The second column of Table 3 shows parents' average contribution broken down by race, number of children, whether the parent is religious or not, age and marital status. None of the demographic variables is significant, except for the parents' age (older parents contribute more than younger ones). Moreover, as for children, parents with larger families contribute less than parents with smaller families (the $\mathrm{p}$-value is 0.056 ).

\subsection{The Correlation between Parents and Children}

We now study the relationship between children's contribution and that of their parents. We do so by regressing children's contributions on parents' contributions. The inference is complicated by the fact that the observations are not independent, as the behavior of each subject is influenced by those of the other people belonging to his or her group. In order to avoid this problem, for each round, we compute the average level of contributions for each group of children and each group of parents. As a result, for each group of children and parents, we are able to compute a time series of average contributions. ${ }^{27}$ Note that the choices of parents and children playing in the same session, but belonging to different groups, are assumed to be statistically independent, since there was no meaningful interaction between subjects belonging to different groups.

In the empirical analysis, the dependent variable is the average per round contribution in each group of children. The independent variable is the average per round contribution by the parents in the corresponding group. ${ }^{28}$ Both the dependent and the independent variable are

\footnotetext{
${ }^{26}$ We chose 3 as a cutoff since the average number of children per family is 3.26.

27 The length of the time series is ten, i.e., the number of rounds.

${ }^{28}$ In the regressions, we include the observations coming from all the groups (including the synthetic groups). Since the synthetic groups include fewer subjects than the regular groups, we use weighted OLS. As a robustness check, we reestimated all the regressions by excluding all the synthetic groups. The results are not affected in any significant way (See the addendum).
} 
centered around their means. ${ }^{29}$ We estimate a panel regression of per round children's contributions over per round parents' contributions. ${ }^{30}$

The main result of the analysis is that a parent's contribution does not affect that of his or her child. As the first column of Table 5 shows, the coefficient on parents' contributions equals 0.09 and it is highly non significant (p-value equals 0.50 ). The absence of correlation is visually confirmed by Figure 1, which plots the rank correlations (over all rounds) between parents' and children's contributions.

Note that this result chimes with one of the results that we found in the previous section, namely that children from larger families tend to contribute less. This seems to reinforce the view that the value formation is primarily the result of environmental factor (e.g., the competition for resources with your siblings).

As a robustness check we reestimated the regression, introducing time-specific dummies, to control for any time-specific effect in contributions $\left(2^{\text {nd }}\right.$ column of Table 5). Moreover, as a second robustness check, we also reestimated the regression by adding, as controls, children's demographic variables: race, sex, school grade, number of children in the family and whether they come from a religious family or not. ${ }^{31}$ The controls are constructed as follows: sex and race are the proportion of subjects in the group who belonged to a given demographic group (i.e., the proportion of women or Hispanics); children's school grade and number of children is the average school grade and the average number of children in the family. All the variables, with the exception of the proportion of boys, Hispanic and children coming from religious families, are centered around their mean to make the results comparable to those of Table 5. Table 6 shows the regression results when we add the demographic variables to the regression. None of the robustness checks affects our result in a significant way. 32

\footnotetext{
${ }^{29}$ Centering around the mean only affects the estimate of the intercept (on which we do not focus) and not the slope (which is what we study). We do so, however, since it makes the results to this estimation comparable to those presented below which include interaction terms.

30 Although each time series of group average contribution is an independent observation, it is possible that within each time series there is heteroskedasticity (in addition to that coming from the different number of subjects in the synthetic groups, which we correct through weighted OLS). For this reason, we correct the standard errors for heteroskedasticity using the Huber-White estimator.

${ }^{31}$ In addition to belonging to a religious denomination, we also used as control the family's religiosity (i.e., the number of times the family goes to religious services per month). The results are not significantly affected.
} 
It is worthwhile to note, however, that both the controls for sex and school grade come out significant: as suggested in the previous section boys contribute less than girls, older children contribute less than younger ones, and children from large families (more than 3 children) contribute less than children from small families.

One could argue that attitudes toward cooperation are best captured by the behavior in the last round (where the only Nash equilibrium for a self-interested player is not to cooperate ${ }^{33}$ ). For this reason we repeated our main regression restricting ourselves to the behavior of parents and children over the last round ( $3^{\text {rd }}$ column of Table 5). The coefficient of parents' contributions on children's contributions again comes out insignificant.

Finally, Harbaugh and Krause (2000) argue that first round contributions could be the best measure of a subject's cooperative behavior since they are not influenced by the other subjects' behavior in the previous rounds. For this reason, we computed the correlation between children's contributions and those of their parents in the first round of the experiment. Note that, since round-1 observations are independent, we can run the regression on individual observations rather than on group averages. Nevertheless, as in the previous robustness checks, the correlation (reported in the last column of Table 5) is small and non significant.

We are also interested in knowing whether a higher correlation between parents and children exists within demographic groups (i.e., in boys versus girls, in Hispanic children versus African American children and in older children versus younger children). The results are reported in Table 7. Note that the interaction terms with boys and children's school grade comes out significant; that is, there is evidence of a positive correlation between boys and their parents. Moreover, there is evidence that correlation is higher (and significant) in younger children and becomes smaller (and insignificant) as children grow older. Finally, the behavior of children coming from larger families is neither more nor less correlated to that of children coming from smaller ones.

\footnotetext{
33 One could argue that, although ours is a finitely repeated game, ten repetitions are sufficient for cooperation to arise as a Nash equilibrium when agents are quasi rational.
} 


\section{Concluding remarks}

A relevant issue for many areas of economics is to understand the formation of the values influencing individual behavior in basic economic settings. Our paper is the first to illustrate how experimental games can be designed to produce new knowledge on this issue. In a simple public goods game, we find that parents' attitudes toward free-riding have little effect on their children's dispositions. Such a lack of correlation between parents and children's behavior provides evidence in favor of the line of research in sociology and psychology suggesting that the family is not the primary locus of values formation.

\section{References}

Alesina, Alberto and Eliana La Ferrara, 2002, "Who Trust Others?" Journal of Public Economics, 85, 207-234.

Anderson, Lisa, Mellor, Jennifer and Jeffrey Milyo, 2004, "Social Capital and Contributions in a Public-Goods Experiment," American Economic Review 94(2), 373-76.

Bisin, Alberto and Thierry Verdier, 2000, “'Beyond the Melting Pot': Cultural Transmission, Marriage, and the Evolution of Ethnic and Religious Traits," Quarterly Journal of Economics, 955988.

Bisin, Alberto and Thierry Verdier, 2001, "The Economics of Cultural Transmission and the Dynamics of Preferences," Journal of Economic Theory, 97(2), 298-319.

Bornhorst, Fabien, Ichino, Andrea and Karl Schlag, 2004, "Trust and Trustworthiness among Europeans: South-North Comparison," CEPR DP 4378.

Charles, Kerwin and Erik Hurst, 2003, "The Correlation of Wealth across Generations," The Journal of Political Economy, 111(6), 1155-1181.

Corneo, Giacomo and Olivier Jeanne, 2006, "Symbolic Values, Occupational Choice and Economic Development," mimeo, Free University of Berlin, Department of Economics.

Doepke, Matthias and Fabrizio Zilibotti, 2005a, "Social Class and the Spirit of Capitalism," Journal of the European Economic Association, 3(2-3), 516-524.

Dohmen, Thomas, Falk, Armin, Huffman, David, Sunde, Uwe, 2006, “The Intergenerational Transmission of Risk and Trust Attitudes," IZA DP 2380. 
Eisenberg, Nancy and Paul H. Mussen, 1989, The Roots of Prosocial Behavior in Children, Cambridge University Press (Cambridge, UK).

Fabes and Eisenberg, 1996, "Meta Analysis of Sex and Age Differences in Prosocial Behavior," Arizona State University Working Paper.

Fernandez, Raquel, Fogli, Alessandra and Claudia Olivetti, 2004, "Mothers and Sons: Prefereence Formation and Female Labor Force Dynamics," Quarterly Journal of Economics 119, 1249-99.

Fershtman, Chaim and Uri Gneezy, 2001, "Discrimination in a Segmented Society: an Experimental Approach," Quarterly Journal of Economics, 116(1), 351-377.

Glaeser, Edward, Laibson, David, Scheinkman, José and Christine L. Soutter, 2000, "Measuring Trust," Quarterly Journal of Economics 115(3), 811-46.

Guiso, Luigi, Sapienza, Paola, and Luigi Zingales, 2004, "Cultural Biases in Economic Exchange," University of Chicago Working Paper.

Guiso, Luigi, Sapienza, Paola, and Luigi Zingales, 2005, “The Role of Social Capital in Financial Development” American Economic Review, 94(3), 525-556.

Harbaugh, William and Kate Krause, 2000, “Children's Altruism in Public Good and Dictator Experiments,” Economic Inquiry 38(1), 95-109.

Harris, Judith, 1995, "Where Is the Child's Environment? A Group Socialization Theory of Development," Psychological Review 102(3), 458-489.

Henrich, J., R. Boyd, S. Bowles, C. Camerer, H. Gintis, R. McElreath and E. Fehr (2001), "In search of Homo Economicus: Experiments in 15 Small-Scale Societies", American Economic Review, 73-79

Hyman, Herbert, 1959, Political Socialization, New York: Free Press of Glencoe.

Jennings, M. Kent and Richard Niemi, 1968, “The Transmission of Political Values from Parent to Child," The American Political Science Review, 62(1), 169-184.

Knack, Stephen and Philipp Keefer, 1997, "Does Social Capital Have an Economic Payoff? A Cross Country Investigation," Quarterly Journal of Economics, 112(4), 1251-1288.

Knowles, Johen, and Andrew Postlewaite, 2005, "Do Children Learn To Save From Their Parents," manuscript, University of Pennsylvania, Department of Economics. 
La Porta, Rafael, Lopez de Silanes, Florencio , Schleifer, Andrei and Robert Vishny, 1997, "'Trust in Large Organizations," American Economic Review, 87(2), 333-338.

Ledyard, John, 1995, "Public Goods: A Survey of Experimental Research," chapter 2 of Alvin Roth and John Kagel (eds.), Handbook of Experimental Economics, Princeton University Press (Princeton, NJ).

Mason, C.F., Phillips, O.R., and D.B. Redington, 1991, "The role of gender in a non-cooperative game," Journal of Economic Behavior and Organization 15, 215-35.

Orbell, J., van de Kragt, A., and R. Dawes, 1988, "Explaining discussion-induced cooperation," Journal of Personality and Social Psychology 54(5), 811-819.

Peters, Elizabeth, Ünür, A. Sinan, Clark, Jeremy and William Schulze, 2004, "Free-Riding and the Provision of Public Goods in the Family: A Laboratory Experiment," International Economic Review 45(1), 283-299.

Putnam, Robert, Leonardi, Robert and Raffaella Nanetti, 1994, Making Democracy Work. Princeton University Press.

Tabellini, Guido, 2005, "Culture and Institutions: Economic Development in the Regions of Europe," mimeo, IGIER, Bocconi University.

Zak, Paul and Stephen Knack, 2001, “Trust and Growth,” Economic Journal, 111(470), 295-321. 
Table 1. Number of Subjects by Session

\begin{tabular}{ccc}
\hline \hline Sessions & Subjects & Groups \\
\hline 1 & 18 & 5 \\
2 & 8 & 3 \\
3 & 12 & 3 \\
\hline \hline
\end{tabular}

Table 2 Demographic Characteristics of the Subjects

\begin{tabular}{|c|c|c|c|c|c|}
\hline \multicolumn{6}{|c|}{ Children } \\
\hline & $\begin{array}{c}\text { Mean/ } \\
\text { Proportion }\end{array}$ & St. Dev. & Min & Max & Obs. \\
\hline Grade, from 0 (Pre-K) to 6 & 2.684 & 1.923 & 0 & 6 & 38 \\
\hline Girls & 0.395 & 0.489 & 0 & 1 & 38 \\
\hline Hispanic & 0.763 & 0.426 & 0 & 1 & 38 \\
\hline \multicolumn{6}{|c|}{ Parents } \\
\hline & $\begin{array}{c}\text { Mean/ } \\
\text { Proportion }\end{array}$ & St. Dev. & Min & Max & Obs. \\
\hline Age & 36.68 & 8.819 & 24 & 63 & 38 \\
\hline Female & 0.974 & 0.160 & 0 & 1 & 38 \\
\hline Married & 0.50 & 0.500 & 0 & 1 & 38 \\
\hline Never Married & 0.263 & 0.441 & 0 & 1 & 38 \\
\hline Divorced, widowed or separated & 0.237 & 0.426 & 0 & 1 & 38 \\
\hline Religious & 0.842 & 0.365 & 0 & 1 & 38 \\
\hline
\end{tabular}


Table 3 Contributions-Descriptive Statistics

\begin{tabular}{|c|c|c|c|c|c|}
\hline \multicolumn{6}{|c|}{ Children } \\
\hline & Mean & St. Dev. & Min & Max & Obs. \\
\hline Tokens shared, first round & 2.39 & 1.5341 & 0 & 5 & 38 \\
\hline Tokens shared, last round & 2.73 & 2.0226 & 0 & 5 & 38 \\
\hline Tokens shared, average & 2.76 & 1.7975 & 0 & 5 & 38 \\
\hline \multicolumn{6}{|c|}{ Parents } \\
\hline & Mean & St. Dev. & Min & Max & Obs. \\
\hline Tokens shared, first round & 2.76 & 0.9982 & 1 & 4 & 38 \\
\hline Tokens shared, last round & 2.95 & 1.469 & 0 & 5 & 38 \\
\hline Tokens shared, average & 2.9 & 1.3459 & 0 & 5 & 38 \\
\hline
\end{tabular}


Table 4. Average Contributions-Demographic Characteristics

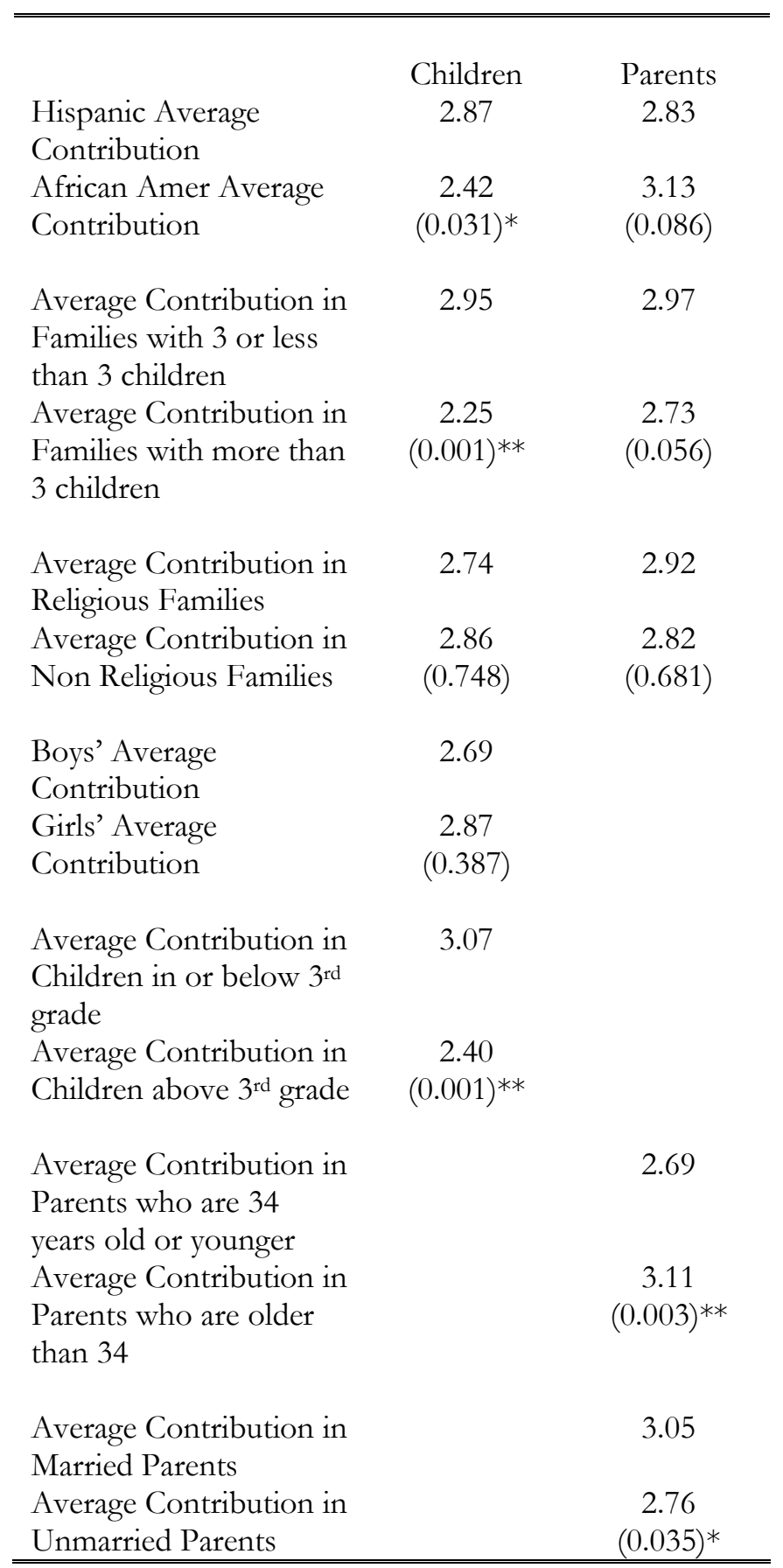

The asterisk represents the result of the test that the mean for each cell is equal to that of the cell above. (e.g., the asterisk in cell 2 of column 1 represents the result of the test that the average contribution in African American and Hispanic parents is the same). * significant at 5\%; ** significant at $1 \%$. 
Table 5. The Relationship Between Children's and Parents' Behavior

\begin{tabular}{lcccc}
\hline \hline & $(1)$ & $(2)$ & $(3)$ & $(4)$ \\
Parents' Mean & & & & \\
Contribution & 0.093 & 0.080 & 0.50 & -0.20 \\
Observations & $(0.496)$ & $(0.567)$ & $(0.46)$ & $(0.41)$ \\
R-squared & 110 & 110 & 11 & 38 \\
\hline \hline
\end{tabular}

Dependent Variable: (1) to (3) average child contribution in each group for each round; (4) individual child contribution in each round. Parents' and children's contributions are centered around their means. Weighted OLS Regression (weight: number of people in each group).

P-values in parenthesis. Standard Errors have been corrected for heteroskedasticity (Huber-White estimator).

* significant at $5 \%$; ** significant at $1 \%$

We estimated the following regressions: (1) Baseline regression; (2) Robustness check with round-specific dummies; (3) Last-round only regression (4) First-round only regression.

\section{Table 6. The Relationship Between Children's and Parents' Behavior- Demographic Controls}

\begin{tabular}{|c|c|c|c|c|c|}
\hline & $\overline{~(1) ~}$ & (2) & (3) & (4) & (5) \\
\hline Parents' Mean & 0.079 & 0.133 & 0.023 & 0.066 & 0.090 \\
\hline Contribution & $(0.528)$ & $(0.305)$ & $(0.830)$ & $(0.610)$ & $(0.503)$ \\
\hline Proportion of Hispanic & $\begin{array}{c}0.766 \\
(0.011)^{*}\end{array}$ & & & & \\
\hline Proportion of Boys & & $\begin{array}{c}-1.281 \\
(0.000)^{* *}\end{array}$ & & & \\
\hline Children Average & & & -0.356 & & \\
\hline School Grade & & & $(0.000)^{* *}$ & & \\
\hline Average Number of & & & & -0.213 & \\
\hline Children & & & & $(0.000)^{* *}$ & \\
\hline Proportion of & & & & & -0.326 \\
\hline Religious Parents & & & & & $(0.405)$ \\
\hline Observations & 110 & 110 & 110 & 110 & 110 \\
\hline R-squared & 0.065 & 0.110 & 0.202 & 0.073 & 0.011 \\
\hline
\end{tabular}

Dependent Variable: average child contribution in each group for each round. Parents' and children's contributions, children's average school grade, and the average number of children are centered around their means.

Weighted OLS Regression (weight: number of people in each group).

P-values in parenthesis. Standard Errors have been corrected for heteroskedasticity (Huber-White estimator).

* significant at $5 \%$; ** significant at $1 \%$ 
Table 7

The Relationship Between Children's and Parents' Behavior Interaction Effects

\begin{tabular}{|c|c|c|c|c|}
\hline & (1) & (2) & (3) & (4) \\
\hline Parents' Mean Contribution & 0.137 & -0.110 & -0.016 & 0.085 \\
\hline & $(0.781)$ & $(0.448)$ & $(0.859)$ & $(0.537)$ \\
\hline Proportion of Hispanic & $\begin{array}{c}0.776 \\
(0.013)^{*}\end{array}$ & & & \\
\hline Hispanic* & -0.062 & & & \\
\hline Parents' Mean Contribution & $(0.911)$ & & & \\
\hline Proportion of Boys & & $\begin{array}{c}-1.235 \\
(0.000)^{* *}\end{array}$ & & \\
\hline Boys* & & 0.544 & & \\
\hline Parents' Mean Contribution & & $(0.038)^{*}$ & & \\
\hline $\begin{array}{l}\text { Children's Average School } \\
\text { Grade }\end{array}$ & & & $\begin{array}{c}-0.173 \\
(0.009)^{* *}\end{array}$ & \\
\hline $\begin{array}{l}\text { Children's School Grade* } \\
\text { Parents' Mean Contribution }\end{array}$ & & & $\begin{array}{c}-0.335 \\
(0.000)^{* *}\end{array}$ & \\
\hline Average Number of Children & & & & $\begin{array}{c}-0.218 \\
(0.000)^{* *}\end{array}$ \\
\hline Average Number of Children * & & & & 0.062 \\
\hline Parents' Mean Contribution & & & & $(0.514)$ \\
\hline Observations & 110 & 110 & 110 & 110 \\
\hline R-squared & 0.065 & 0.123 & 0.382 & 0.074 \\
\hline
\end{tabular}

Dependent Variable: average child contribution in each group for each round. Parents' and children's contributions, children's average school grade, and the average number of children are centered around their means.

Weighted OLS Regression (weight: number of people in each group).

P-values in parenthesis. Standard Errors have been corrected for heterosckedasticity (Huber-White estimator).

$*$ significant at 5\%; $* *$ significant at $1 \%$ 
Figure 1: Correlations and Rank Correlations between Parents' and Children's Contributions

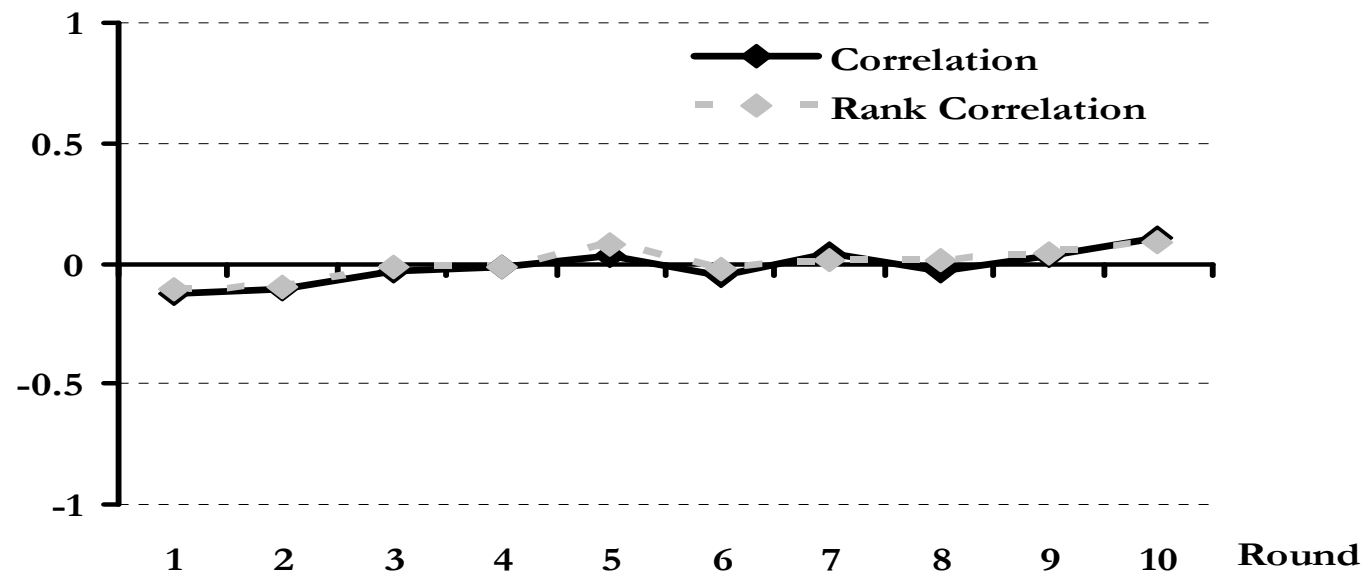




\section{Addendum to "The Transmission of Values from Parents to Children: Experimental Evidence from a Sample of African American and Hispanic Families"}

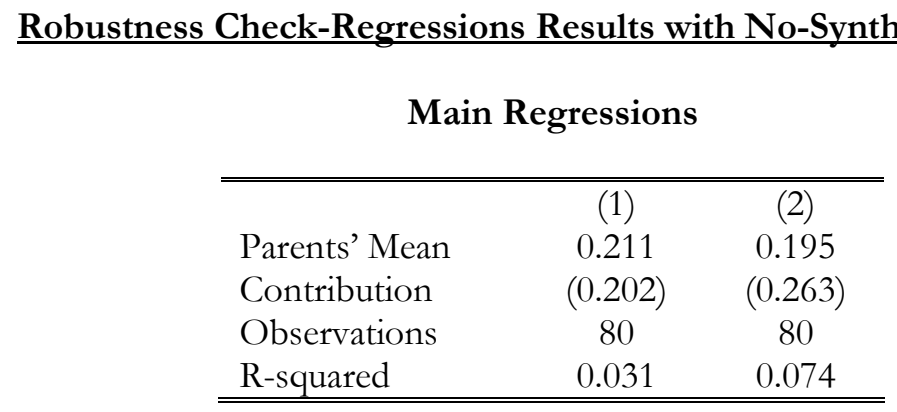

Dependent Variable: average child contribution in each group for each round. Parents' and children's contributions are centered around their means.

Weighted OLS Regression (weight: number of people in each group).

P-values in parenthesis. Standard Errors have been corrected for heterosckedasticity (Huber-White estimator).

* significant at $5 \%$; ** significant at $1 \%$

We estimated the following regressions: (1) Baseline regression; (2) Robustness check with round-specific dummies

Regressions with the controls

\begin{tabular}{|c|c|c|c|c|c|}
\hline & (1) & (2) & (3) & (4) & (5) \\
\hline Parents' Mean & 0.139 & 0.161 & 0.216 & 0.168 & 0.375 \\
\hline Contribution & $(0.322)$ & $(0.291)$ & $(0.059)$ & $(0.293)$ & $(0.060)$ \\
\hline Proportion of & 1.877 & & & & \\
\hline Hispanic & $(0.000)^{* *}$ & & & & \\
\hline $\begin{array}{l}\text { Proportion of } \\
\text { Boys }\end{array}$ & & $\begin{array}{c}-1.700 \\
(0.000)^{* *}\end{array}$ & & & \\
\hline Children's & & & -0.530 & & \\
\hline Average School & & & $(0.000)^{* *}$ & & \\
\hline Grade & & & & & \\
\hline Average Number & & & & -0.173 & \\
\hline of Children & & & & $(0.001)^{* *}$ & \\
\hline Proportion of & & & & & 1.691 \\
\hline Religious Parents & & & & & $(0.088)$ \\
\hline Observations & 80 & 80 & 80 & 80 & 80 \\
\hline R-squared & 0.190 & 0.172 & 0.402 & 0.075 & 0.058 \\
\hline
\end{tabular}

Dependent Variable: average child contribution in each group for each round. Parents' and children's contributions, children's average school grade, and the average number of children are centered around their means.

Weighted OLS Regression (weight: number of people in each group)

P-values in parenthesis. Standard Errors have been corrected for heterosckedasticity (Huber-White estimator).

* significant at $5 \%$; ** significant at $1 \%$ 


\section{Regressions with interaction terms}

\begin{tabular}{|c|c|c|c|c|}
\hline & (1) & (2) & (3) & (4) \\
\hline Parents' Mean & -0.198 & -0.043 & -0.044 & 0.150 \\
\hline Contribution & $(0.691)$ & $(0.909)$ & $(0.798)$ & $(0.336)$ \\
\hline $\begin{array}{l}\text { Proportion of } \\
\text { Hispanic }\end{array}$ & $\begin{array}{c}1.811 \\
(0.000)^{* *}\end{array}$ & & & \\
\hline $\begin{array}{l}\text { Proportion of } \\
\text { Boys }\end{array}$ & & $\begin{array}{c}-1.750 \\
(0.000)^{* *}\end{array}$ & & \\
\hline Children's & & & -0.177 & \\
\hline Average School & & & $(0.339)$ & \\
\hline Grade & & & & \\
\hline $\begin{array}{l}\text { Average Number } \\
\text { of Children }\end{array}$ & & & & $\begin{array}{l}-0.144 \\
(0.032)^{*}\end{array}$ \\
\hline Hispanic*Parents' & 0.364 & & & \\
\hline Mean & $(0.547)$ & & & \\
\hline Contribution & & & & \\
\hline Boys* & & 0.394 & & \\
\hline Parents' Mean & & $(0.526)$ & & \\
\hline Contribution & & & & \\
\hline Children's School & & & -0.372 & \\
\hline Grade*Parents' & & & $(0.041)^{*}$ & \\
\hline Mean & & & & \\
\hline Contribution & & & & \\
\hline Average Number & & & & -0.201 \\
\hline of Children & & & & $(0.242)$ \\
\hline *Parents' Mean & & & & \\
\hline Contribution & & & & \\
\hline Observations & 80 & 80 & 80 & 80 \\
\hline R-squared & 0.192 & 0.174 & 0.439 & 0.085 \\
\hline
\end{tabular}

Dependent Variable: average child contribution in each group for each round. Parents' and children's contributions, children's average school grade, and the average number of children are centered around their means.

Weighted OLS Regression (weight: number of people in each group).

P-values in parenthesis. Standard Errors have been corrected for heterosckedasticity (Huber-White estimator).

* significant at $5 \%$;* significant at $1 \%$ 


\section{Robustness Check-Regression Results excluding the father from the sample}

\section{Main Regressions}

\begin{tabular}{lcc}
\hline \hline & $(1)$ & $(2)$ \\
Parents' Mean & 0.019 & 0.005 \\
Contribution & $(0.894)$ & $(0.973)$ \\
Observations & 110 & 110 \\
R-squared & 0.000 & 0.038 \\
\hline \hline
\end{tabular}

Dependent Variable: average child contribution in each group for each round. Parents' and children's contributions are centered around their means.

Weighted OLS Regression (weight: number of people in each group).

P-values in parenthesis. Standard Errors have been corrected for heterosckedasticity (Huber-White estimator).

* significant at 5\%; ** significant at 1\%

We estimated the following regressions: (1) Baseline regression; (2) Robustness check with round-specific dummies.

Regressions with the controls

\begin{tabular}{|c|c|c|c|c|c|}
\hline & (1) & (2) & (3) & (4) & (5) \\
\hline Parents' Mean & 0.004 & 0.072 & 0.076 & -0.010 & 0.021 \\
\hline Contribution & $(0.976)$ & (0.603) & $(0.499)$ & $(0.938)$ & $(0.884)$ \\
\hline $\begin{array}{l}\text { Proportion of } \\
\text { Hispanic }\end{array}$ & $\begin{array}{c}0.910 \\
(0.005)^{* *}\end{array}$ & & & & \\
\hline $\begin{array}{l}\text { Proportion of } \\
\text { Boys }\end{array}$ & & $\begin{array}{c}-1.261 \\
(0.000)^{* *}\end{array}$ & & & \\
\hline Children's & & & -0.383 & & \\
\hline Average School & & & $(0.000) * *$ & & \\
\hline Grade & & & & & \\
\hline $\begin{array}{l}\text { Average Number } \\
\text { of Children }\end{array}$ & & & & $\begin{array}{c}-0.274 \\
(0.000)^{* *}\end{array}$ & \\
\hline Proportion of & & & & & -0.634 \\
\hline Religious Parents & & & & & (0.138) \\
\hline Observations & 110 & 110 & 110 & 110 & 110 \\
\hline R-squared & 0.068 & 0.079 & 0.177 & 0.093 & 0.013 \\
\hline
\end{tabular}

Dependent Variable: average child contribution in each group for each round. Parents' and children's contributions, children's average school grade, and the average number of children are centered around their means.

Weighted OLS Regression (weight: number of people in each group).

P-values in parenthesis. Standard Errors have been corrected for heterosckedasticity (Huber-White estimator).

* significant at $5 \%$;* significant at $1 \%$ 


\section{Regressions with interaction terms}

\begin{tabular}{|c|c|c|c|c|}
\hline & (1) & (2) & (3) & (4) \\
\hline Parents' Mean Contribution & $\begin{array}{l}-0.601 \\
(0.319)\end{array}$ & $\begin{array}{l}-0.075 \\
(0.622)\end{array}$ & $\begin{array}{l}-0.103 \\
(0.301)\end{array}$ & $\begin{array}{l}-0.043 \\
(0.771)\end{array}$ \\
\hline Proportion of Hispanic & $\begin{array}{c}0.831 \\
(0.011)^{*}\end{array}$ & & & \\
\hline Proportion of Boys & & $\begin{array}{c}-1.231 \\
(0.000)^{* *}\end{array}$ & & \\
\hline $\begin{array}{l}\text { Children's Average School } \\
\text { Grade }\end{array}$ & & & $\begin{array}{c}-0.209 \\
(0.003)^{* *}\end{array}$ & \\
\hline Average Number of Children & & & & $\begin{array}{c}-0.269 \\
(0.000)^{* *}\end{array}$ \\
\hline $\begin{array}{l}\text { Hispanic* } \\
\text { Parents' Mean Contribution }\end{array}$ & $\begin{array}{c}0.646 \\
(0.325)\end{array}$ & & & \\
\hline Boys* & & 0.337 & & \\
\hline Parents' Mean Contribution & & $(0.275)$ & & \\
\hline Children's School Grade* & & & -0.320 & \\
\hline Parents' Mean Contribution & & & $(0.00)^{* *}$ & \\
\hline Average Number of Children * & & & & -0.097 \\
\hline Parents' Mean Contribution & & & & $(0.454)$ \\
\hline Observations & 110 & 110 & 110 & 110 \\
\hline R-squared & 0.075 & 0.082 & 0.306 & 0.096 \\
\hline
\end{tabular}

Dependent Variable: average child contribution in each group for each round. Parents' and children's contributions, children's average school grade, and the average number of children are centered around their means.

Weighted OLS Regression (weight: number of people in each group).

P-values in parenthesis. Standard Errors have been corrected for heterosckedasticity (Huber-White estimator).

* significant at $5 \%$; ** significant at $1 \%$. 